Bijdragen tot de Dierkunde, 52 (2): 186-190 - 1982

\title{
IMPLICATION, CONDITIONALITY AND TAXONOMIC STATEMENTS
}

\author{
by
}

\author{
IAN R. BALL \\ Institute of Taxonomic Zoology, University of Amsterdam, \\ P.O. Box 20125, 1000 HC Amsterdam, The Netherlands
}

\begin{abstract}
Popper's falsifiability criterion, cast in the form of modus tollens, or $((\mathrm{P} \supset \mathrm{Q}) . \sim \mathrm{Q}) \supset \sim \mathrm{P}$, has often been applied to phylogenetic and cladistic theories. A severe criticism of such application is here examined. Questions concerning the universality, strict or numerical, of the propositions involved are irrelevant, but it is clear nevertheless that some workers have used modus tollens in an inappropriate way. Reliance on it is incorrect if the implicational statement, $P \supset Q$, is either a definitional or stochastic conditional. But if it is framed as a causal conditional then a Popperian approach to phylogenetics remains viable, although it is doubtful that this is true also of cladistics, which eschews a causal approach.
\end{abstract}

\section{ZUSAMMENFASSUNG}

Popper's Kriterium der Falsifikation ist gefaßt in der Form von modus tollens, oder $((\mathrm{P} \supset \mathrm{Q}) . \sim \mathrm{Q}) \supset \sim \mathrm{P}$, und ist häufig in phylogenetischen und kladistischen Theorien angewendet worden. Eine ernsthafte Kritik dieses Vorgehens ist das Thema dieses Beitrages. Fragen hinsichtlich die Universalität, strikt oder numerisch, der einschlägigen Aussagen habe keine Relevanz, aber es unterliegt keinem Zweifel, daß bestimmte $W$ issenschaftler modus tollens auf eine falsche Weise gebraucht haben. Verwendung von modus tollens ist unrichtig, wenn die implikative Aussage, $\mathbf{P} \supset \mathbf{Q}$, entweder eine definitorische oder eine stochastische Konditionalität ist. Aber wenn die implikative Aussage gefaBt ist wie ein kausaler Konditional, dann bleibt eine Anwendung der phylogenetischen Systematik im Sinne Popper's eine richtige Methode. Es muß bezweifelt werden, ob dasselbe für die kladistische Systematik gilt, weil sie eine kausale Behandlung abweist.

The views of Sir Karl Popper on the philosophy of science (Popper, 1959, 1968, 1972; Schilpp, 1974) have had a profound effect on the activities of systematic biologists. In particular practitioners of phylogenetics (Bonde, 1975, 1977; Miles, 1975; Wiley, 1975, 1981; Gaffney, 1979) and transformed cladistics (Platnick, 1979; Nelson \& Platnick, 1981) have claimed to be working within the framework of the hypothetico-deductive model so skilfully advocated by Popper. In a recent paper, however, Panchen (1982) has severely criticised that claim and has gone so far as to state that before the methodology of cladism ${ }^{1}$ can become trustworthy it will have to abandon its pretence to the hypothetico-deductive method.

The principle of falsification employed by Popper is cast in the form of modus tollens (Popper, 1959: 75) and it is a charge of misuse or misunderstanding of that mode by phylogeneticists that constitutes one of Panchen's main criticisms (Panchen, 1982: 312-313). I believe Panchen to be right in his criticism in so far as his chosen example goes and wrong in the conclusions that he draws from that, viz., that phylogeneticists will have to abandon their pretence to the hypothetico-deductive model. Panchen deserves credit for pinpointing an area of woolly thinking in systematics nevertheless, and I shall attempt some further clarification here.

The deductive argument of modus tollens comprises a statement of implication (if $P$ then $Q$ ), the denial of the consequent (not $Q$ ) and therefore the denial of the antecedent $(\therefore$ not $\mathrm{P})$. In the language of the logicians this is as follows 2 :

$$
\begin{aligned}
& \mathrm{P} \supset \mathrm{Q} \\
& \sim \mathrm{Q} \text { or }((\mathrm{P} \supset \mathrm{Q}) \cdot \sim \mathrm{Q}) \supset \sim \mathrm{P} \\
& \therefore \sim \mathrm{P}
\end{aligned}
$$

Modus tollens is an exercise in pure logic and it is not necessary that there be some connection between the antecedent and the consequent of an implication statement in order for it to be valid;

1 By cladism Panchen seems to mean the taxonomic philosophy of those who advocate an evolutionary underpinning to cladistic theories together with the so-called transformed cladists who deny the evolutionary connotations of cladograms. I shall refer to the former group as phylogeneticists and to the latter simply as cladists, their respective fields being phylogenetics and cladistics.

2 Symbols are explained fully in Appendix 1. I acknowledge here the value of the logic text by Bradley \& Swartz (1979). 
to suppose otherwise is a common and widespread error (Popper, 1959: 75, fn*1). Falsification, as a part of this mode, may be regarded as an exercise in applied logic, and in so far as this type of logic comes to be applied to systematic biology, or indeed any other science, we do reasonably expect there to be such connections as just mentioned, in which case we are dealing more properly with material conditional statements.

Material conditional statements can take several forms ${ }^{3}$. Logical conditionals, or ones of definition ( $P=$ unmarried male, $Q=$ is a bachelor) express a true proposition if and only if the proposition expressed by the antecedent logically implies the proposition expressed by the consequent. Causal conditionals $(P=$ there is a gale, $Q=$ the sea is rough) express a true proposition if and only if the antecedent causally implies the consequent. Stochastic conditionals $(P=$ there are six plates on the table, $Q=$ there are six persons expected for dinner) express a true proposition if and only if the antecedent increases the probability of (i.e. probabilifies) the proposition expressed by the consequent.

All these conditionals have the form of $P \supset Q$ and, equally important, all may be expressed as a sentence that says that it is not the case that the proposition expressed by the antecedent of that sentence be true while the proposition expressed by the consequent is false. Or,

$$
\sim(\mathrm{P} . \sim \mathrm{Q})
$$

Thus, when $P$ and $Q$ are replaced by propositions we may legitimately ask are there any possible conditions under which, or any possible worlds in which, $\sim(\mathrm{P} . \sim \mathrm{Q})$ is false? The significance of this will become apparent later in this paper. It may also be noted that Popperian falsification is concerned not with logical (or definitional) conditionals but primarily with causal ones. Popper (1959) has also attempted, however, to apply his methods to probabilistic statements.

Panchen's example of modus tollens concerns tetrapod relationships -

8 I have omitted, as here irrelevant, those of a legal type (P - showing racial discrimination, $Q=$ you will be prosecuted).
If the porolepiforms are the sister-group of some or all tetrapod groups,

then they will be among those fish known to be choanate. i.e. $\mathrm{P} \supset \mathrm{Q}$

Porolepiforms are not among those fish known to be choanate. i.e. $\sim Q$

Therefore porolepiforms are not the sister-group of any tetrapod group. i.e. $\therefore \sim$ P.

Not being a specialist in vertebrate zoology I must accept as given the truth of the propositions, and the logical argument is impeccable. But for Panchen this is not Popperian falsification. He gives as his reasons (a) that the consequent does not constitute a new prediction from the antecedent, and that the two propositions are either (b) a matter of definition or (c) contingent (i.e. neither necessary nor impossible). Although something of a digression it is necessary first to dispose of argument (c). Panchen makes the point that this means that the statement is not a strictly universal statement but one that describes a spatiotemporally limited state of affairs, and he cites Kitts (1977) in support. To me this seems to be a continuation of a widespread, though false, view that for Popper only strictly universal statements are a part of science. Thus Kitts (1977: 192) writes that the knowledge claims of systematic zoology are not expressed in strictly universal statements and are therefore, according to Popper's analysis of scientific knowledge, different from the knowledge claims of scientific theories.

It is certainly true that Popper was led to the significance of the asymmetry of proof and disproof by a consideration of the logical structure of strictly universal statements, and it is true that he wrote that science is a system of strictly universal statements (Popper, 1959). But these statements cannot be taken as meaning that only strictly universal statements are testable or that only strictly universal statements form the content of science, and this has been made abundantly clear by Popper himself in his reply to a criticism by Kneale (1974) (Popper, 1974: 988-989). Certainly singular statements can be a part of empirical science as defined by Popper and this too is made clear in "The Poverty of Historicism" where Popper defends the view that history is characterised by its interest in actual, singular, or specific events, 
rather than in laws or generalisations, a view which he claims as compatible with his analysis of scientific method (Popper, 1957: 30).

In the field of systematic zoology this misunderstanding seems first to have arisen from a mistake in the exposition of Popper's views given for systematists by two leading theoreticians: "...the only requirement a statement must meet to be testable is that it be universal, so that it excludes or forbids something" (Platnick \& Gaffney, 1978: 140). This is certainly not in accord with Popper's ideas. And nor can the misunderstanding of Kitts (also Panchen, 1982: 311) be saved by reference to the difference between numerically universal and strictly universal statements as one that affects the validity of our arguments for this, too, can be dismissed in Popper's own words: ..."The question whether the laws of science are strictly or numerically universal cannot be settled by argument. It is one of those questions which can be settled only by an agreement or convention". (Popper, 1959: 63.)

The problem with the example used by Panchen does not reside in questions concerning the universality of the propositions. The real objections to the argument concerning the classification of the porolepiforms are covered by the points (a) and (b) above of Panchen, viz., that, in effect, the question is one of logic and not one of causality. The conditional statement the use of the term 'sister-group' notwithstanding, is merely one of simple definition and does not represent a causal scientific hypothesis 4. For such definitional

4 Any predicate $\mathrm{F}$ will determine a rlass, i.e. $\{x: \mathrm{F} x\}$, and an object a belongs to this class if and only if $F$ is true of 2. That is to say:

$$
a \varepsilon\{x: \mathrm{F} x\} \text { iff } \mathrm{Fa}
$$

Thus one can say ( $c f$. the porolepiform argument on p. 187) that all and every $x$ (i.e. members of a given class) possess property $F$, or:

$$
(\forall x) F x
$$

But probably most taxonomists operate, albeit unconsciously, with the formulation

$$
(x \varepsilon A) \supset F_{x}
$$

as a stochastic conditional referring to polythetic sets, i.e. if $\boldsymbol{x}$ is a member of $\Lambda$ then probably it has property $F$ (or it has a greater probability of possessing $F$ then if it were not a member of $\mathrm{A}$ ). Of course this can be valid for any classification and it is especially so, by definition for those derived from numerical phenetics. The phylogeneticist however, seeks greater certainty (see also Kitts, 1977: 186-190). conditionals it is a fact, by definition, that for all possible worlds it can never be the case that $\sim(P . \sim Q)$ is false. In short Panchen is right. The modus tollens argument concerning the tetrapods is valid, but it is not Popperian falsification because its material conditional is definitional and not causal. I would even go so far as to say that analogous contra-arguments could be applied to those cladists who rely entirely on pattern analysis, and prediction therefrom, (e.g. Nelson, 1978) without reference to any causal principles, and that is why I have elsewhere suggested that cladistics as a formal system is a sterile enterprise (Ball, 1981: 676).

Nevertheless, the fact that some systematists have confused Popperian falsification with the logicians' modus tollens does not mean that all have used inapplicable arguments. Thus, taking the 'paradigm case' of the three taxon statement, $(\mathrm{X}(\mathrm{YZ}))$, where of three taxa forming a monophyletic group $\mathrm{Y}$ and $\mathrm{Z}$ share a unique common ancestor not shared by $\mathrm{X}$ and thus are more closely related to each other than either is to $\mathrm{X}$, then from this certain predictions and prohibitions can be derived. Using the theory of evolution, and its generally accepted corollaries, as a covering law it may be said that if $(\mathrm{P})$ the specified hypothesis concerning the phylogenetic relationships of $\mathrm{X}$, $Y$ and $Z$ is true then (Q) homologous character states unique to ( $X$ and $Y$ ) and ( $X$ and $Z$ ) will not occur. The negation of $Q$, finding these character distributions, will then be the denial of the consequent and thus the falsification of the hypothesis.

We may then ask whether as regards this hypothesis there are any conditions, or any possible worlds, in which $\sim($ P. $\sim Q)$ is false? The answer is an emphatic yes. For, as Gaffney (1979: 96-97) has written "When multiple series of characters are used it is often the case that all three possible hypotheses relating three taxa will appear to be falsified by one or more character distributions". The principal reason for this would be convergent evolution, that is to say, when convergence occurs $\sim(P . \sim Q)$ is false or, our original predictions are valid only in a world in which convergence does not occur.

Thus, when apparent falsification occurs we 
must first check that our observations have been made within the boundaries, within that possible world, for which our original hypothesis was intended to apply. The principle of parsimony is totally irrelevant here and in this $I$ am in full agreement with Panchen (1982: 313) and there is no question that it has been used in a bizarre manner by many cladists and phylogeneticists. Parsimony itself is no test and it only gives us a way of choosing rationally a hypothesis suitable for testing. But what is legitimate, or so it seems to $\mathrm{me}$, is to provisionally preserve the hypothesis by questioning the validity or applicability of the falsifying experience. Thus a character distribution of (XY), apparently falsifying the hypothesis $(\mathrm{X}(\mathrm{YZ}))$ may be found in a modified state in $Z$ after careful examination and thus become a synapomorphy for (XYZ). Alternatively observation may prove that the conditions in $\mathrm{X}$ and $\mathrm{Y}$ are not unique but also occur outside of the group $(\mathrm{XYZ})$, in which case it probably is a symplesiomorphy, or close inspection may prove that the conditions in $\mathrm{X}$ and $\mathrm{Y}$ are not really homologous. These are not ad boc procedures, they are efforts to determine if our observations have been made in any of the possible worlds where $\sim(P . \sim Q)$ is false.

Most scientific theories apply only under specified conditions. Boyle's Law fails at very low pressures, Newton's second Law fails at very high velocities, and so on. Thus it is normal that for theories of science there are conditions under which $\sim($ P. $\sim$ Q) is false. As Heisenberg (1974: 43) put it, "We no longer say 'Newtonian mechanics is false and must be replaced by quantum mechanics, which is correct' ...rather... 'classical mechanics is a consistent self-enclosed scientific theory. It is a strictly 'correct' description of nature wherever its concepts can be applied" ". The fact that the conditions under which $\sim(\mathrm{P} . \sim \mathrm{Q})$ is false for systematic theories are more frequent than is usual in the physical sciences, for example, may make life difficult. But to say something is difficult is not to say it is invalid and, as Smart (1968) has observed, an exception to a generalisation of natural history is even to be expected, in a way in which an exception to a putative law of nature comes as a surprise and is a serious matter.
Synapomorphies will corroborate a given phylogenetic hypothesis but if we are to evaluate potential falsifiers we need to study, among other things, analogy and criteria for its recognition, adaptation, convergence and parallelism. In their obsession with synapomorphies, cladists and some phylogeneticists have indeed legislated these phenomena out of systematic biology, and in their ensuing poverty, or laziness, they have often been led to resort to invalid uses of implication and parsimony to preserve their enterprise. But properly considered phylogenetics remains fully compatible with the hypothetico-deductive method.

\section{ACKNOWLEDGEMENTS}

My colleagues Ronald Sluys, Pjotr Oosterbroek, Jan Wattel, and Theo van Koolwijk kindly read and criticised an earlier version of this essay.

\section{REFERENCES}

BALL, I. R., 1981. The order of life-towards a comparative biology. Nature, London, 294: 675-676.

Bradley, R. \& N. Swartz, 1979. Possible worlds: an introduction to logic and its philosophy: i-xxi, 1-391. (Basil Blackwell, Oxford).

BONDE, N., 1975. Origin of "higher groups": viewpoints of phylogenetic systematics. Colloques internationaux du Centre National de la Recherche Scientifique, 218: 293-324.

- 1977 . Cladistic classification as applied to vertebrates. In, M. K. Hecht, P. C. GoOdY \& B. M. Hecht (Eds.), Major patterns in vertebrate evolution: 741-804. (Plenum Press, New York).

GAFFNEY, E. S., 1979. An introduction to the logic of phylogeny reconstruction. In, J. Cracraft \& $\mathrm{N}$. EldREDGE (Eds.), Phylogenetic analysis and paleontology: 79-111. (Columbia University Press, New York).

HeisenberG, W., 1974. The notion of a "closed theory" in modern science: 39-46. In, Across the frontiers: i-xxii, 1-1229. (Harper Torch Books, New York).

Krrrs, D. B., 1977. Karl Popper, verifiability, and system. atic zoology. Syst. Zool., 26: 185-194.

KNEALE, W. C., 1974. The demarcation of science: $205-217$. In, ScHILPP (1974).

Miles, R. S., 1975. The relationships of the Dipnoi. Colloques internationaux du Centre National de la Recherche Scientifique, 218: 133-148.

Nelson, G., 1978. Classification and prediction: a reply to Kitts. Syst. Zool., 27: 216-218.

Nelson, G. \& N. Platnick, 1981. Systematics and biogeography: cladistics and vicariance: i-xi, 1-567. (Columbia University Press, New York).

Panchen, A. L., 1982. The use of parsimony in testing phylogenetic hypotheses. Zool. J. Linn. Soc., 74: 305-328.

Platinick, N., 1979. Philosophy and the transformation of cladistics. Syst. Zool., 28: 537-546.

Platnick, N. \& E. S. Gaffney, 1978. Evolutionary biology: a Popperian perspective. Syst. Zool., 27: 137-141. 
POPPER, K. R., 1957. The poverty of historicism: i-vii, 1-166. (Routledge \& Kegan Paul, London).

—, 1959. The logic of scientific discovery: 1-480. (University of Toronto Press, Toronto).

, 1968. Conjectures and refutations: i-xiii, 1-417. (Harper Torch Books, New York).

- 1972 . Objective knowledge: i-x, 1-380. (Clarendon Press, Oxford).

, 1974. The philosopher replies: 961-1197. In, ScHILPP (1974).
SChIlpP, P. A. (Ed.), 1974. The philosophy of Karl Popper, I: i-xvi, 1-670; II: i-xii, 671-1323. (Open Court, La Salle, Illinois).

SMART, J. J. C., 1968. Between science and philosophy: i-ix, 1-363. (Random House, New York).

WILeY, E. O., 1975. Karl R. Popper, systematics, and classification: a reply to Walter Bock and other evolutionary taxonomists. Syst. Zool., 24: 233-242.

, 1981. Phylogenetics: i-xv, 1-439. (John Wiley and Sons, New York).

\section{APPENDIX}

Symbols used in the text have the following meanings:

F any predicate such as 'has four legs', 'is choanate'

$\varepsilon \quad$ 'is a member of'

iff 'if and only if'

$\mathbf{P}, \mathbf{Q} \quad$ sentences as yet unspecified

$\boldsymbol{x}$ an object or individual member of a set

$\forall \quad$ 'for all' or 'for every'

- 'and'

$\supset$ 'if...then...' Thus, $P \supset Q$ means 'if $P$ then $Q$ '

$\sim$ 'not' or 'it is not the case that'

$\therefore \quad$ 'therefore'

(\}) indicates a set

Examples:

$\sim$ (P. $\sim$ Q) means it is not the case that we can have both $P$ and not $Q$ together

$(\forall x) \mathrm{F} x \quad$ means that for every $x \mathrm{~F}$ is true of $x$, or all $x$ have the property $\mathrm{F}$

$\{x, y\} \quad$ is the set comprising just $x$ and $y$

$\{x: F x\} \quad$ is the set of all things satisfying the predicate F. Thus, if $F$ is 'feathered biped' then $\{x: F x\}$ would be the set 'birds'

Received: 31 August 1982 